\title{
RESENHA: NOVAS PRÁTICAS ALIMENTARES NO MERCADO GLOBAL
}

\author{
Andre Luiz de Souza ${ }^{1}$
}

O objetivo deste texto é resenhar a obra Novas Práticas Alimentares no Mercado Global, uma coletânea de textos organizada por Julia Sílvia Guivant e Carmen Rial, ambas da Universidade Federal de Santa Catarina (UFSC), e Gert Spaargarem, da Universidade de Wageningnen, Holanda, publicada em 2010 pela Editora da UFSC. Na obra, aborda-se a percepção global sobre novas convergências do mercado alimentar, além de se destacarem os aspectos da sustentabilidade e um novo olhar para a saúde a partir da alimentação, à luz das discussões da Antropologia e da Sociologia.

O livro contém I4 capítulos e está estruturado em quatro partes. A primeira parte da obra intitula-se Perspectivas Globais. No primeiro capítulo, Ooster, Guivant e Spaargaren pontuam a consolidação de uma terceira fase dos sistemas alimentares. A fase inicial era orientada pela produção, a segunda pelo consumo e a terceira se insere no setor dos supermercados como o principal condutor e tomador de decisões. Nessa conjuntura, a organização e a distribuição da produção e do consumo tornam-se pauta global, na qual, consequentemente, as redes ou cadeias de supermercados têm uma posição privilegiada. A alta demanda de produção alimentícia faz com que as redes de supermercados controlem o sistema alimentar conforme a dinâmica de produção, adaptando-se aos interesses dos consumidores. Essa mudança de hábitos contribui para reterritorializar a economia local ou global.

O segundo capítulo, escrito por Arthur Mol, discorre sobre a relação entre a revolução das Tecnologias da Informação e Comunicação (TIC) e a reforma ambiental. Para o autor, as TIC sempre tiveram importância nos processos de governança ambiental no tempo e no espaço, resultando em uma restruturação das práticas da governança ambiental, diferenciando-se das convencionais. Novas práticas reorganizaram o sistema alimentar e possibilitaram novas

\footnotetext{
r Sociólogo, doutorando em Sociologia pela Universidade Federal do Rio Grande do Sul, Porto Alegre, Rio Grande do Sul, Brasil.- Integrante GEPAD: www.ufrgs.br/agrifood - ORCID: https://orcid.org/oooo-oooz-2283-5274. Email:andresouza@ufrgs.br
} 
estratégias da verdadeira governança informacional sobre o meio ambiente e os alimentos. Os consumidores estão interligados, e isso demanda mudanças das próprias corporações em direção à sustentabilidade, mesclando interesses globais em um sistema de governança entre setores públicos e privados. Pensar novas práticas alimentares requer estratégias que contemplem as interações globais, já que a demanda é uma necessidade do planeta de reconstruir novas redes de agentes capazes de modicar as estruturas vigentes.

Nessa lógica, no terceiro capítulo, Oosteveer e Spaargaren enfatizam os mecanismos inovadores para o enverdecimento das cadeias globais de alimentos. Para os autores, nas últimas décadas, têm ocorrido mudanças profundas no fornecimento de alimentos, tanto no que diz respeito à produção e à distribuição, quanto à segurança dos produtos fornecidos. Nesse caso, os mecanismos reguladores de governança são de extrema importância para o desenvolvimento e para a institucionalização de novos regimes regulatórios em nível global. Para os autores, essas práticas de produção e de consumo de alimentos são retiradas das realidades locais e reencaixadas em redes e fluxos globais. Esse desencaixe causa uma perda de identidade alimentar e uma preocupação na saúde pessoal do consumidor. Nesse sentido, é fundamental uma governança dos alimentos na modernidade global entre os sistemas locais e globais, com participações de diversos atores públicos e privados.

Finalizando a primeira parte da obra, o quarto capítulo, produzido por Carmem Rial, a partir de um prisma antropológico, aborda as práticas alimentares e suas interpretações. Segundo a autora, para ajudar os indivíduos a escolher bem seus alimentos, é preciso educá-los, informálos e lutar contra certos obstáculos representados pela ignorância, tais como as pressões comerciais e a publicidade.

A segunda parte da obra, denominada O Mercado de Orgânicos, é composta por três capítulos. No primeiro, Eduardo João Moro apresenta uma metodologia de análise das estratégias dos supermercados para a venda de alimentos orgânicos. Considerando a crescente busca por alimentos orgânicos e a oferta desses produtos em supermercados, as feiras e lojas especializadas passaram a ter um papel secundário na venda de tais produtos, como observado em países europeus, nos Estados Unidos e também no Brasil. Para o autor, a guinda de interesse na população em consumir alimentos de qualidade impôs um novo ritmo para os sistemas alimentares, forjando 
novos hábitos e estilos de vida. Por isso, compreender as estratégias dos supermercados é compreender o consumo de maneira geral, desde as pequenas lojas até as grandes redes.

Paulo Silveira e Gisele Guimarães, no segundo capítulo, analisam a relação de produçãodistribuição-consumo de produtos orgânicos processados no estado do Rio Grande dos Sul. Salientam o papel das grandes redes de supermercados como geradores de opções aos consumidores. Afirmam que os mercados de produtos orgânicos são um campo econômico em construção. No entanto, observam o controle das grandes redes de supermercados em construir marcas próprias de orgânicos, disponibilizando-as aos consumidores. Os supermercados são espaços consolidados para expandir esse novo nicho de consumo diante das mudanças dos hábitos alimentares, e grandes redes como Carrefour, Pão de açúcar e Walmart constroem arranjos nas políticas de formalização contratual para alcançarem os consumidores e assim expandirem seus lucros.

Rosana Garcia, no terceiro capítulo, discute as relações de comercialização entre produtores orgânicos e supermercados. Destaca que os supermercados recebem pouco destaque nas pesquisas acadêmicas sobre as percepções dos agricultores que com comercializam com tais estabelecimentos. Ademais, a maioria dos agricultores tem dificuldade de inserção dos seus produtos nas redes de supermercados, principalmente no que diz respeito aos aspectos da padronização e de estética dos alimentos. Diante dessa realidade, a autora pesquisou o perfil dos agricultores orgânicos da Grande Florianópolis (SC), observando uma ressignificação da ruralidade, na sua forma de percebê-la e de vivenciá-la. A opção de se trabalhar com agricultura orgânica surgiu como uma oportunidade no mercado emergente. O estudo demostrou que a comercialização de produtores orgânicos com supermercados na Grande Florianópolis interfere no meio rural, gerando uma dinâmica complexa, que possibilita novas alternativas de coexistência dos meios rural e urbano, gera renda e emprego, promovendo novos hábitos de relações sociais e econômicas diante da nova ruralidade.

A terceira parte da obra é denominada Alimentos Funcionais. O primeiro capítulo é de Márcia Grisotti, intitulado Alegações de saúde dos alimentos funcionais: emergência e impacto na saúde individual e coletiva. A autora enfatiza que as inter-relações entre alimentação e saúde não são novas. Desde os primórdios, o ser humano mantém essas relações entre alimentação, dieta e saúde, o que indica que há muito a ser estudado sobre essa temática. Para a pesquisadora, as alegações de 
saúde de alimentos funcionais estão entre as mais complexas e controversas feitas pelas agências regulatórias, gerando dubiedade na eficácia da alimentação, já que é crescente a quantidade de produtos vendidos nos supermercados com supostos benefícios à saúde. Tal controvérsia, por sua vez, está no fato de ser um alimento realmente saudável ou ser apenas mais uma mercadoria imposta aos consumidores. Para ajudar na discussão, a pesquisadora ressalta o papel da ciência, que deve ser levada em consideração tanto pelas agências governamentais, pela indústria alimentícia e pelos consumidores.

O segundo capítulo foi produzido por André Luiz Bianco, que discorre sobre a ambivalência dos alimentos funcionais. $\mathrm{O}$ autor destaca que o processo de urbanização do século $\mathrm{XX}$ foi protagonista no avanço de doenças crônicas, as quais comprometeram a qualidade de vida e os investimentos do Estado em políticas públicas vinculadas a dietas saudáveis. Diante disso, os alimentos funcionais tornaram-se sinônimo de saúde diante das novas necessidades da população. Contudo, existe uma discrepância entre as definições de alimentos funcionais, e o efeito disso é que o consumidor fica cada vez mais desorientado, em meio ao fluxo contínuo de informação, não sendo capaz de assimilá-lo.

Seguindo nessa meandra, o último capítulo tem como título $O$ mercado dos iogurtes funcionais, escrito por Cécile Raud. A autora ressalta que nos últimos anos os consumidores passaram a ser confrontados com novos produtos alimentares que, além de suas funções nutricionais, têm também funções fisiológicas na promoção de saúde e prevenção de doenças. Os iogurtes funcionais estão entre os alimentos mais procurados, devido aos benefícios ao sistema digestivo. Essas mudanças são analisadas a partir da Nova Sociologia Econômica (NSE), que, segundo a pesquisadora, auxiliam na interpretação e na compreensão das dinâmicas e formas econômicas organizadas ao redor da noção de "construção social de mercado". Assim sendo, os alimentos funcionais não representam apenas um novo nicho de mercado, mas uma nova fronteira do mercado de alimentos.

A última parte do livro é denominada Estratégias Institucionais em relação ao mercado verde. Inicialmente, Marcia da Silva Mazon, em seu trabalho A transição nutricional e sua sociologia: o dilema alimentar no século XXI, ressalta que, a partir do advento da revolução verde nos anos de I96o, as pessoas passaram a reorganizar os seus sistemas alimentares com a introdução de novas tecnologias na agricultura, o que possibilitou um aumento na produtividade; nessa perspectiva, 
muitos alimentos toraram-se commodities. A autora argumenta que, depois de quatro décadas de um aumento significativo de alimentos no mundo, surgiram novas preocupações com relação à oferta de alimentos; a revolução verde perdeu o otimismo de acabar com a fome no mundo e passou a produzir doenças. Começam a surgir, nesse contexto, doenças vinculadas aos hábitos alimentares. O sistema alimentar padrão produziu uma geração de obesos que ultrapassou à de desnutridos. O problema agora não é a fome, mas o tipo de alimentos que gera não apenas uma qualidade ruim dos produtos, mas também doenças. A pesquisadora defende que esse novo padrão de alimentos ocasiona uma sociedade doentia, que substituiu os padrões alimentares por alimentos artificiais e geneticamente modificados.

No capítulo subsequente, Marília Luz David discorre sobre os direitos do consumidor com relação aos alimentos transgênicos. Segundo a autora, o consumo representa muito mais do que apenas o ato de consumir, incluiu outras categorias do ponto de vista sociológico e, mais recentemente, os direitos dos consumidores. A seu ver, o direito do consumidor é a parte mais vulnerável dentro das relações de consumo. A autora analisa as relações jurídicas dos Estados Unidos e posteriormente do Brasil para mostrar o processo de organização desses direitos, articulando a relação entre consumo e cidadania na sociedade dita "moderna". Na discussão, o que se evidencia é que o consumidor fica à mercê das grandes empresas que monopolizam o comércio de sementes, ameaçando a diversidade da agricultura familiar. Há vários testes científicos que indicam contaminação nos produtos transgênicos, porém, a inércia do Estado em criar leis que regulamentam esse sistema é evidente. Os interesses econômicos prevalecem perante os direitos dos consumidores, e a cidadania submete-se aos fatores econômicos.

O penúltimo capítulo da obra, intitulado Além do que se vê: uma análise do sistema de fiscalização dos riscos alimentares, é de autoria de Ana Carolina Cassiano. De acordo com a autora, hoje o Brasil conta com amplo aparato de regras e instrumentos de controle da qualidade dos alimentos, no entanto, há vários riscos alimentares presentes, com destaque a dois: o caráter da própria modernidade e os limites do conhecimento técnico-científico. O Brasil, mesmo fazendo parte internacionalmente do Codex Alimmentarius e contando com suas próprias leis, ainda apresenta fraudes na manipulação dos alimentos, as quais são resultado da ineficiência dos órgãos fiscalizadores, que acabam por estimular práticas incoerentes na produção de alimentos. 
O capítulo final da coletânea, produzido por Viviane Kraieski de Assunção, apresenta uma discussão sobre as relações entre alimentação e recepção de programas sobre culinária. A pesquisadora enfatiza que os meios de comunicação atuam como importantes fontes de reprodução de discursos, o que impacta também as práticas e saberes alimentares. Os programas culinários são, conforme argumenta a autora, uma entidade fixa e estável, produzidos e vendidos como mercadoria. A partir da análise de dois programas televisivos, a autora argumenta que esses difundem hábitos de consumo nos seus telespectadores, mas que estão muitas vezes fora do contexto das pessoas. Essa forma pedagógica é exercida em diversos programas, que induzem o telespectador a incorporar uma realidade falsa no seu cotidiano. Assim, para a pesquisadora, a mídia cria um processo intensivo de socialização de hábitos e práticas de consumo para mercadorizar os sentidos da vida.

Após apresentarmos de maneira geral a obra, é possível afirmar que se trata de um suporte fundamental e leitura obrigatória para aqueles que desejam analisar as novas práticas alimentares diante de um processo cada vez mais de padronização das dietas alimentares, na junção da monopolização das cadeias de mercados globais e locais. A obra possibilita compreender que esse sistema produz um conjunto de inversão de valores que não representa a saúde alimentar, mas, em muitos casos, produz doenças nas mais diversas práticas de difusões de mercadorias revestidas de alimentos. Nesse sentido, devemos pensar em novas práticas alimentares para reverter a atual conjectura do sistema agroalimentar que visa ao lucro e ao controle das cadeias produtivas. A atual forma de produzir alimentos está envenenando o solo, a biodiversidade os agricultores e os consumidores.

\section{Referência}

GUIVANT, J.; SPAARGAREM, G.; RIAL, C. (Orgs.). Novas Práticas Alimentares no Mercado Global. Florianópolis: Ed. da UFSC, 2010. 